\title{
Glutamate and Dopamine Transmission from Midbrain Dopamine Neurons Share Similar Release Properties But Are Differentially Affected by Cocaine
}

\author{
Martín F. Adrover, ${ }^{\star}$ Jung Hoon Shin, ${ }^{\star}$ and Veronica A. Alvarez \\ Section on Neuronal Structure, National Institute on Alcohol Abuse and Alcoholism, National Institutes of Health, Bethesda, Maryland 20892
}

\begin{abstract}
Synaptic transmission between ventral tegmental area and nucleus accumbens (NAc) is critically involved in reward-motivated behaviors and thought to be altered in addiction. In addition to dopamine (DA), glutamate is packaged and released by a subset of mesolimbic DA neurons, eliciting EPSCs onto medium spiny neurons in NAc. Little is known about the properties and modulation of glutamate release from DA midbrain terminals and the effect of cocaine. Using an optogenetic approach to selectively activate midbrain DA fibers, we compared the properties and modulation of DA transients and EPSCs measured using fast-scan cyclic voltammetry and whole-cell recordings in mouse brain slices. DA transients and EPSCs were inhibited by DA receptor $\mathrm{D}_{2} \mathrm{R}$ agonist and showed a marked paired-pulse depression that required $2 \mathrm{~min}$ for full recovery. Cocaine depressed EPSCs amplitude by $50 \%$ but enhanced the overall DA transmission from midbrain DA neurons. AMPA and NMDA receptor-mediated EPSCs were equally inhibited by cocaine, suggesting a presynaptic mechanism of action. Pharmacological blockage and genetic deletion of $\mathrm{D}_{2} \mathrm{R}$ in $\mathrm{DA}$ neurons prevented the cocaine-induced inhibition of EPSCs and caused a larger increase in DA transient peak, confirming the involvement of presynaptic $\mathrm{D}_{2} \mathrm{R}$. These findings demonstrate that acute cocaine inhibits DA and glutamate release from midbrain DA neurons via presynaptic $D_{2} R$ but has differential overall effects on their transmissions in the NAc. We postulate that cocaine, by blocking DA reuptake, prolongs DA transients and facilitates the feedback inhibition of DA and glutamate release from these terminals.
\end{abstract}

Key words: co-release; cocaine; D2 receptors; dopamine; feedback inhibition; glutamate

\section{Introduction}

Dopaminergic neurons in ventral tegmental area (VTA) project densely to the core and shell subregions of the NAc in which DA release is induced by natural stimuli and also by drugs of abuse. A subset of DA neurons in VTA express vesicular glutamate transporter-2 (VGluT2; Kawano et al., 2006; Yamaguchi et al., 2011,2013 ) and are able to package and release glutamate (Sulzer et al., 1998; Chuhma et al., 2004; Dal Bo et al., 2004, 2008; Mendez et al., 2008; Bérubé-Carrière et al., 2009; Hnasko et al., 2010). Recent studies using optogenetic stimulation of axon terminals originating from VTA DA neurons provided unequivocal evidence of glutamate release by inducing AMPA receptor (AMPAR)-mediated

\footnotetext{
Received Nov. 26, 2013; revised Jan. 9, 2014; accepted Jan. 17, 2014.

Author contributions: M.F.A., J.H.S., and V.A.A. designed research; M.F.A. and J.H.S. performed research; M.F.A. and J.H.S. analyzed data; M.F.A., J.H.S., and V.A.A. wrote the paper.

This study was funded by the Intramural Programs of National Institute on Alcohol Abuse and Alcoholism (NIAAA) and National Institute of Neurological Disorders and Stroke Grant ZIA-AA000421. We are grateful to Roland Bock [NIAAA/National Institutes of Health (NIH)] for developing the analysis software, Dr. Fumihito Ono (NIAAA/NIH) for sharing their confocal microscope, and Drs. Karl Deisseroth (Stanford University, Stanford, CA) and Nicole Calakos (Duke University, Durham, NC) for providing the channelrhodopsin-2 constructs and Drd1-tdTomato mice, respectively. We also thank the members of the Alvarez laboratory for their valuable comments on this manuscript.

*M.F.A. and J.H.S. contributed equally to this work.

The authors declare no competing financial interests.

Correspondence should be addressed to Dr. Veronica A. Alvarez, National Institute on Alcohol Abuse and Alcoholism/National Institutes of Health, 5625 Fishers Lane, Bethesda, MD 20892. E-mail: alvarezva@mail.nih.gov.

DOI:10.1523/JNEUROSCI.4958-13.2014

Copyright $\odot 2014$ the authors $\quad 0270-6474 / 14 / 343183-10 \$ 15.00 / 0$
}

EPSCs on medium spiny neurons (MSNs) of the NAc shell (Stuber et al., 2010; Tecuapetla et al., 2010). Furthermore, deletion of VGluT2 in VTA DA neurons completely abolished the EPSCs (Stuber et al., 2010).

Although there is consensus that a subset of VTA DA neurons also releases glutamate in the NAc, it is still debated whether both transmitters are coreleased from the same synaptic vesicle, separate vesicles, or even different release sites. Hnasko et al. (2010) showed that vesicular monoamine transporter-2 (VMAT2) coimmunoprecipitated with VGluT2 and that glutamate cotransport stimulates monoamine uptake into vesicles, supporting the hypothesis that glutamate and DA are packaged in the same vesicles and released from the same release sites. However, electron microscopy studies failed to find double staining for VGluT2 and tyrosine hydroxylase (TH) in DA axon varicosities of adult rodents (BérubéCarrière et al., 2009, 2012; Moss et al., 2011), favoring the hypothesis of separate packaging of glutamate and DA into vesicles and distinct release sites. In-depth characterization of the functional properties of glutamate and DA release from DA terminals will provide new evidence to help evaluate these two hypotheses.

Conditional knock-out mice lacking VGluT2 only in DA neurons display altered locomotor response to amphetamine (Birgner et al., 2010) and cocaine (Hnasko et al., 2010) and enhanced sucrose and cocaine self-administration (Alsiö et al., 2011). These results suggest a role for fast excitatory glutamatergic transmission from VTA DA neurons in regulating the physiological re- 
sponse to stimulant drugs. Thus, it is important to better understand the effect of cocaine on excitatory glutamatergic transmission from VTA DA neurons. Furthermore, the acute effect of cocaine on DA transmission requires additional examination in light of studies suggesting that cocaine, in addition to inhibiting the DA transporter and blocking DA reuptake, augments DA release by mobilizing the reserved pool of DA synaptic vesicles (Lee et al., 2001; Venton et al., 2006; Kile et al., 2010).

The current study compares the synaptic properties of dopaminergic and glutamatergic transmission from VTA DA neurons that are triggered by either conventional electrical stimulation or optogenetic stimulation, which selectively activates fibers from VTA DA neurons. The results show that the release properties of DA and glutamate from VTA DA terminals are very similar and that, although cocaine inhibits DA and glutamate release through presynaptic dopamine receptor $\mathrm{D}_{2} \mathrm{R}$, it potentiates $\mathrm{DA}$ and depresses glutamate transmission.

\section{Materials and Methods}

Animals. All experiments were performed in accordance with guidelines from the National Institute on Alcohol Abuse and Alcoholism Animal Care and Use Committee. Experiments used male heterozygote B6.SJL-Slc6a3 $3^{\text {tml.1(cre)Bkmn} / J ~ m i c e ~(c a t a l o g ~ \# 006660 ; ~ T h e ~ J a c k s o n ~}$ Laboratory), referred to here as DAT $T^{+I I R E S-c r e}$ mice, which carry the DA transporter IRES-cre allele to coexpress both genes from the endogenous promoter (Bäckman et al., 2006). For some experiments, male $D r d 2^{\text {loxP/loxP }} ; D A T^{+/ I R E S-c r e}$ mice, referred to here as autoDrd2KO, which carry two conditional alleles for the $\mathrm{DA} \mathrm{D}_{2} \mathrm{R}$ gene, and the DAT $T^{+/ I R E S-c r e}$ mice (Bello et al., 2011) were also used. For other experiments, male Drd1-tdTomato;DAT $T^{+/ I R E S-c r e}$ mice were generated by crossing DAT $T^{+/ I R E S-c r e}$ with Drd1-tdTomato (Shuen et al., 2008) and were used to distinguish $\mathrm{D}_{1} \mathrm{R}$-expressing and $\mathrm{D}_{2} \mathrm{R}$-expressing MSNs in the NAc shell. All mice are in the C57BL/6 background and housed on a $12 \mathrm{~h}$ light/dark cycle (6:30 A.M. to 6:30 P.M.) with food and water ad libitum.

Surgery and stereotaxic injection of adeno-associated virus-channelrhodopsin 2 vectors. Mice (4-6 weeks old) were anesthetized by inhalation of isoflurane-oxygen mixture and were placed in a stereotaxic frame (model 963; David Kopf Instruments). Craniotomies were performed using stereotaxic coordinates according to the atlas of Franklin and Paxinos (2007) (anteroposterior, $-3.25 \mathrm{~mm}$; mediolateral, $\pm 0.50 \mathrm{~mm}$; dorsoventral, $-4.50 \mathrm{~mm}$; coordinates from bregma). Recombinant adeno-associated virus (AAV) vectors with Cre recombinase-dependent expression of channelrhodopsin2 (ChR2) protein, AAV5-EF1a-DIOhChR2(H134R)-EYFP $\left(6 \times 10^{12} \mathrm{IU} / \mathrm{ml}\right)$, were bilaterally injected into the VTA using a 30 gauge beveled metal needle that was connected with polyethylene tubing to a $2 \mu \mathrm{l}$ Hamilton syringe. The injection volume $(300 \mathrm{nl})$ and flow rate $(100 \mathrm{nl} / \mathrm{min})$ were controlled with an injection pump (World Precision Instruments), and the needle was removed 4 min after the injection ended to allow solution to spread in the brain tissue. A minimum of 2 weeks of incubation was allowed to ensure sufficient ChR2 expression before recordings. For some experiments, AAV5-EF1a-DIO-hChR2(H134R)-mCherry $\left(4 \times 10^{12} \mathrm{IU} / \mathrm{ml}\right)$ was used. All viral vectors were obtained from Gene Therapy Center Vector Core at the University of North Carolina.

Slice preparation. Mice (8-10 weeks old) were anesthetized with isoflurane and killed by decapitation. Brains were quickly removed, mounted, and sliced in a vibratome (VT-1200S; Leica) in an ice-cold cutting solution containing the following (in mM): 225 sucrose, 13.9 $\mathrm{NaCl}, 26.2 \mathrm{NaHCO}_{3}, 1 \mathrm{NaH}_{2} \mathrm{PO}_{4}, 1.25$ glucose, $2.5 \mathrm{KCl}, 0.1 \mathrm{CaCl}_{2}, 4.9$ $\mathrm{MgCl}_{2}$, and 3 kynurenic acid. The obtained sagittal slices $(240 \mu \mathrm{m})$ were recovered for $20 \mathrm{~min}$ at $33^{\circ} \mathrm{C}$ in artificial CSF (ACSF; in mM: $124 \mathrm{NaCl}, 1$ $\mathrm{NaH}_{2} \mathrm{PO}_{4}, 2.5 \mathrm{KCl}, 1.3 \mathrm{MgCl}_{2}, 2.5 \mathrm{CaCl}_{2}, 20$ glucose, $26.2 \mathrm{NaHCO}_{3}$, and 0.4 ascorbic acid) and maintained in the dark at room temperature before recordings. For recordings, slices were submerged in a chamber with continuous perfusion $(2 \mathrm{ml} / \mathrm{min})$ of ACSF containing D-serine $(10 \mu \mathrm{M})$ and gabazine $(5 \mu \mathrm{M})$ and kept at $32^{\circ} \mathrm{C}$ using an in-line heater (Harvard Apparatus).

Fast-scan cyclic voltammetry. Fast-scan cyclic voltammetry (FSCV) was performed in the NAc shell. Cylindrical carbon-fiber electrodes were prepared with T650 fibers ( $6 \mu \mathrm{m}$ diameter, $\sim 150 \mu \mathrm{m}$ of exposed fiber) inserted into a glass pipette. The carbon-fiber electrode was held at -0.4 $\mathrm{V}$ versus $\mathrm{Ag} / \mathrm{AgCl}$ and a triangular voltage ramp $(-0.4$ to +1.2 and back to $-0.4 \mathrm{~V}$ at $0.4 \mathrm{~V} / \mathrm{ms}$ ) was delivered every $100 \mathrm{~ms}$. DA transients were evoked by electric or optogenetic stimulations. For electrical stimulation, a glass pipette filled with ACSF was placed near the tip of the carbon fiber $(\sim 100-200 \mu \mathrm{m})$, and a rectangular pulse $(0.2 \mathrm{~ms})$ was applied every 2 min. The amplitude of the current pulse $(100-250 \mu \mathrm{A})$ was adjusted to use the minimal current needed to generate a maximal and stable responses. For optogenetic stimulation, a fiber optic ( $200 \mu \mathrm{m} / 0.22$ numerical aperture; Thorlabs) connected to a diode pumped blue laser (473 $\mathrm{nm}, 10-25 \mathrm{~mW}$; CrystaLaser) was placed over the carbon fiber, and pulses ( $\sim 700 \mu \mathrm{W}, 0.2 \mathrm{~ms}$ ) were delivered every $2 \mathrm{~min}$. No attempt was made to match the amplitudes of the signal evoked by electrical or optogenetic stimulation. Data were collected with a retrofit head stage (CB7B/EC with $5 \mathrm{M} \Omega$ resistor) using a Multiclamp 700B amplifier after low-pass filtering at $10 \mathrm{kHz}$ and digitized at $100 \mathrm{kHz}$ using pClamp10 software (all from Molecular Devices). For analysis, baseline voltammograms before stimulation were averaged and subtracted from the voltammograms during and after stimulation (Fig. 1D), and transients were calculated from the oxidation peak region using custom-written analysis software in Igor Pro (WaveMetrics). Paired-pulse ratios (PPRs) were calculated as the amplitude ratio of the second/first response, and, for short intervals $(0.1-2 \mathrm{~s})$, the second transient was calculated by subtracting the single-pulse transient from the paired-pulse transient.

The current peak amplitude of the evoked DA transients were converted to DA concentration according to the postexperimental calibration of the carbon-fiber electrodes with DA (1-3 $\mu \mathrm{M})$ applied locally through a glass pipette in the recording chamber.

Electrophysiology. Visualized whole-cell voltage-clamp recording was performed in NAc shell MSNs using recording electrodes, with a resistance $\sim 3-4 \mathrm{M} \Omega$, that were filled with an internal solution containing the following (in mM): 120 cesium methanesulfonate, $20 \mathrm{CsCl}, 10$ HEPES, 0.2 EGTA, 10 sodium phosphocreatine, $4 \mathrm{Na}_{2}$-ATP, and $0.4 \mathrm{Na}-\mathrm{GTP}, \mathrm{pH}$ 7.25 (290-310 mOsm). Cells were voltage clamped at -70 or $+40 \mathrm{mV}$, and data were collected using a Multiclamp 700B amplifier (Molecular Devices) after low-pass filtering at $1 \mathrm{kHz}$ and digitized at $5 \mathrm{kHz}$ using pClamp10 software. Electrical and optogenetic stimulation was performed as described above, and single or paired pulses $(0.2-0.5 \mathrm{~ms}$ long) were delivered every 2 min to evoke EPSCs. AMPAR-mediated EPSCs were recorded when holding cells at $-70 \mathrm{mV}$ in the presence of the NMDA receptor (NMDAR) antagonist 3- $((R)-2$-carboxypiperazin-4yl)-propyl-1-phosphonic acid (CPP; $5 \mu \mathrm{M})$. NMDAR-mediated EPSCs were calculated by subtracting the EPSCs recorded at $+40 \mathrm{mV}$ before $\mathrm{CPP}$ to the EPSCs recorded at $+40 \mathrm{mV}$ after CPP. AMPA/NMDA ratios were calculated by dividing the AMPAR-mediated EPSCs to the NMDAR-mediated EPSCs. IPSCs were recorded at $0 \mathrm{mV}$ in ACSF in the absence of gabazine, using the same optogenetic stimulation $(0.2 \mathrm{~ms}$ every $2 \mathrm{~min}$ ) and an interval of $5 \mathrm{~s}$.

Drugs. Cocaine $[\mathrm{HCl}]$ was purchased from Sigma or provided by National Institute on Drug Abuse. Sulpiride, quinpirole, and D-serine were purchased from Tocris. Gabazine, tetrodotoxin, kynurenic acid (sodium salt), 2,3dihydroxy-6-nitro-7-sulfonyl-benzo[f] quinoxaline (NBQX), and CPP were obtained from Abcam. All other chemicals were from Sigma.

Statistical analyses. Statistical analysis was performed with Igor Pro or Prism (GraphPad Software) using unpaired two-tailed Student's $t$ test unless otherwise stated. Paired Student's $t$ test, one-way and two-way ANOVA, and Tukey's tests were used when appropriate, and Bonferroni's test for multiple comparisons was used for post hoc analysis.

\section{Results}

Electrical and optogenetic stimulation evoke undistinguishable DA transients under basal conditions ChR2 tagged with yellow fluorescence protein (YFP) was selectively expressed in midbrain dopaminergic neurons of $D A T^{+/ I R E S-c r e}$ mice 

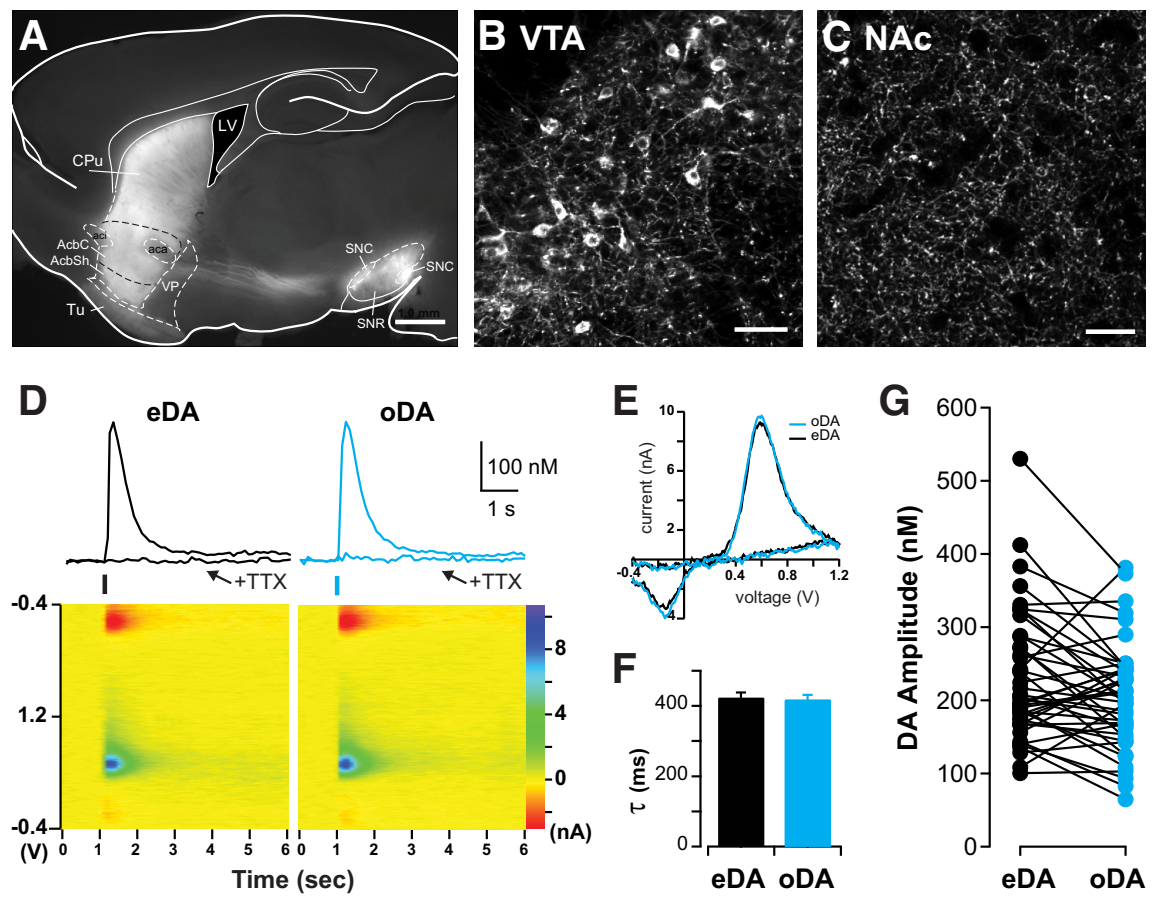

Figure 1. DA transients evoked by electrical and optogenetic stimulation share common properties. $\boldsymbol{A}$, Fluorescence image of sagittal brain section of DAT ${ }^{+/ I R E S-c r e}$ mouse showing labeled midbrain dopaminergic neurons expressing ChR2 and their projections to the NAc and dorsal striatum overlaid onto corresponding sections from the mouse brain atlas (Franklin and Paxinos, 2007). Scale bar, $1 \mathrm{~mm}$. B, Confocal image of labeled cell bodies in the VTA. Scale bar, $50 \mu \mathrm{m}$. C, Confocal image in the NAc region showing dense innervation of labeled DA axons. No labeled cell bodies were found in the striatum. Scale bar, $50 \mu \mathrm{m}$. D, Top, Representative DA transients evoked by alternating electrical stimulation (eDA, black traces) and optogenetic stimulation (oDA, blue traces) recorded using FSCV in the NAc shell before and after TTX (500 nm) application. Bottom, Color plot voltammogram of eDA and oDA transients before TTX application. $\boldsymbol{E}$, Superimposed examples of current-voltage plot of eDA and oDA signals showing the characteristic oxidation and reduction peaks of DA. Decay time constant $(\boldsymbol{F} ; \tau$, mean \pm SEM) and amplitude $(\boldsymbol{G})$ of eDA and $0 \mathrm{DA}$ transients obtained from the same slice preparation ( $n=44$ slices). AcbC, accumbens core; AcbSh, accumbens shell; $C P u$, caudate putamen; LV, lateral ventricle; SNC, substantia nigra pars compacta; SNR, substantia nigra pars reticulata; Tu, olfactory tubercle; VP, ventral pallidum.

using viral gene transfer by stereotaxic bilateral injections. Figure $1 \mathrm{~A}$ shows the typical pattern of fluorescence expression shown in sagittal brain slices after at least 2 weeks from injection $(29 \pm 3 \mathrm{~d})$ with labeled somas in the VTA and substantia nigra pars compacta (Fig. $1 B$ ) and labeled axonal projections in the NAc and dorsal striatum (Fig. 1C).

DA transients were recorded with a carbon-fiber electrode using FSCV in the shell region of the NAc in brain slices (Fig. 1D). DA transients were evoked using electrical stimulation of all passing fibers, referred to as eDA, and optogenetic stimulation to selectively activate the axons of dopaminergic midbrain neurons that innervate the NAc shell, referred to as oDA transients. Electrical and optogenetic stimulation were interleaved in the same slice to evoke eDA or oDA transients by brief $(0.2 \mathrm{~ms})$ pulses of either current or $473 \mathrm{~nm}$ light. Both stimulations evoked DA transients that were similar in magnitude and time course (Fig. $1 D$ ). The pseudocolor voltammograms (Fig. 1D) and the current-voltage plots (Fig. 1E) for eDA and oDA overlapped and showed the oxidation peak at approximately $+0.6 \mathrm{~V}$ and reduction peak at approximately $-0.2 \mathrm{~V}$ that characterizes DA molecules. The superimposed eDA and oDA current-voltage plots showed the oxidation and reduction voltages that correspond to DA (Fig. 1E), indicating that the change in the current with the applied voltage is attributable to the increase in the DA level. These eDA and oDA transients required activation of voltagedependent sodium channels because the application of TTX $(0.5$

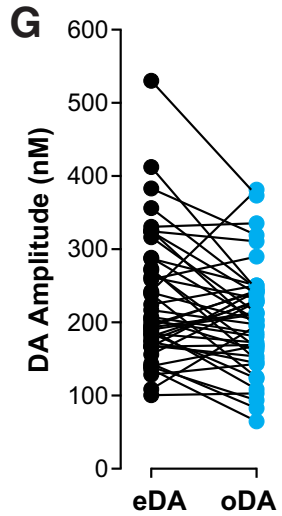

$\mu \mathrm{M})$ completely abolished both transients (Fig. $1 D$; remaining oDA $=1.4 \pm 1.3 \%$, remaining $\mathrm{eDA}=1.0 \pm 0.7 \%$ of baseline, $n=4$ slices $/ 3$ mice; two-way repeatedmeasures ANOVA, main effect of TTX, $F_{(1,3)}=33.35, p=0.01$, no effect of stimulation or interaction). The DA transient rise time was $168 \pm 7 \mathrm{~ms}$ for $\mathrm{eDA}$ and $166 \pm 3 \mathrm{~ms}$ for oDA transients, whereas the decay time constant $\tau$ was $425 \pm 14 \mathrm{~ms}$ for eDA and $415 \pm 16 \mathrm{~ms}$ for oDA transients (Fig. $1 F ; n=44$ slices/17 mice; paired $t$ test, $p=0.26$ ). The peak amplitude of eDA transients was $232 \pm 16 \mathrm{~nm}$ and for oDA transients was $210 \pm 17 \mathrm{nM}$ (Fig. $1 G ; n=44$ slices/17 mice; paired $t$ test, $p=0.1)$. Hence, under baseline conditions, oDA transients had similar electrochemical properties, amplitude, and kinetics to eDA transients recorded in the same slice.

\section{Glutamate- and DA-mediated transmission from midbrain neurons have similar properties}

Glutamate EPSCs evoked by electrical stimulation (eEPSCs) or by optogenetic stimulation (oEPSCs) were recorded in MSNs of the NAc shell (Fig. 2A). The delay between the stimulation and the onset of postsynaptic responses was $2.58 \pm 0.14$ $\mathrm{ms}$ for eEPSCs and $2.35 \pm 0.09 \mathrm{~ms}$ for oEPSCs ( $n=12$ cells $/ 4$ mice). oEPSCs were insensitive to $D_{1} R$ and $D_{2} R$ antagonists (data not shown), indicating a direct monosynaptic connection (Stuber et al., 2010; Tecuapetla et al., 2010).

eEPSCs and oEPSCs were completely abolished by coapplication of an AMPAR antagonist, NBQX, and an NMDAR antagonist, CPP (data not shown), indicating the activation of both types of ionotropic glutamate receptors on the postsynaptic membrane of MSNs. AMPAR-mediated EPSCs were recorded at $-70 \mathrm{mV}$ and NMDAR-mediated EPSCs at $+40 \mathrm{mV}$ (Fig. $2 A$; see Materials and Methods). The average AMPA/NMDA ratio of eEPSCs was more than four times larger than oEPSCs $(2.8 \pm 0.3$, $n=9$ cells $/ 3$ mice for eEPSCs; $0.6 \pm 0.1, n=10$ cells $/ 3$ mice for oEPSCs; $p<0.0001$; Fig. $2 B$ ). This low AMPA/NMDA ratio observed for oEPSCs is indicative of a larger contribution of NMDAR to the postsynaptic response from midbrain DA fiber. Furthermore, this result shows that the postsynaptic properties of glutamatergic synapses from midbrain DA fibers are different from the majority of glutamatergic synapses evoked by electrical stimulation that presumably arise from cortex, amygdala, thalamus, and hippocampus.

PPR is a measure of use-dependent plasticity and describes changes in the probability of neurotransmitter release when consecutive stimulations are delivered close in time. When two stimuli were delivered at $1 \mathrm{~s}$ intervals, the amplitude of the second response was similar to the first response for eEPSCs $(0.96 \pm 0.04 ; n=9$ cells $/ 3$ mice; Fig. 2C). In contrast, the second response was highly depressed in the case of oEPSCs and oDA transients at 1 s intervals $(0.29 \pm 0.02$, $n=10$ cells $/ 3$ mice for oEPSCs; $0.24 \pm 0.03, n=11$ slices $/ 7$ mice for oDA). When PPRs were measured with interstimulus intervals 
(ISIs) ranging from $100 \mathrm{~ms}$ to $120 \mathrm{~s}$, the PPR curves of eEPSCs showed some facilitation at the shorter intervals but maintained a ratio of $\sim 1$ with longer ISI (Fig. $2 D$ ). In contrast, the oDA transients and oEPSCs showed a marked paired-pulse depression with a maximum of $\sim 1 \mathrm{~s}$ interval (Fig. $2 D$ ). The two PPR curves were remarkably similar over the whole interval range and showed that at least $120 \mathrm{~s}$ is required for full recovery. These PPR results show that (1) the glutamate release from midbrain DA neurons is differently affected by previous activity than the other afferent glutamate terminals, and (2) the midbrain DA terminals and glutamate terminals may share common release characteristics, favoring the hypothesis for the existence of a subset of VTA terminals that release both neurotransmitters from the same presynaptic compartment.

The contribution of $\mathrm{D}_{2} \mathrm{R}$-mediated inhibition to the paired-pulse depression was examined by recording PPR values of oEPSCs in the presence of the $\mathrm{D}_{2} \mathrm{R}$ antagonist sulpiride. PPR values in sulpiride were significantly higher for 1 and $2 \mathrm{~s}$ intervals (from $0.29 \pm 0.02$ to $0.38 \pm 0.01$ for $1 \mathrm{~s}, n=11$ cells $/ 3$ mice, $p=0.001$; and from $0.39 \pm 0.03$ to $0.56 \pm 0.06$ for $2 \mathrm{~s}$, $n=6$ cells $/ 3$ mice, $p=0.017$ ) but not for $5 \mathrm{~s}$ intervals (from $0.44 \pm 0.02$ to $0.45 \pm$ $0.02, n=20$ cells $/ 6$ mice, $p=0.296$ ). This is in agreement with previous studies that showed an upward shift in the eDA PPR curve by $\mathrm{D}_{2} \mathrm{R}$ antagonist for intervals $\leq 2 \mathrm{~s}$ (Phillips et al., 2002) and DA uncaginginduced depression lasting only up to $5 \mathrm{~s}$ (Lee et al., 2002).

GABA release from midbrain DA neurons in the striatum was shown recently (Tritsch et al., 2012). GABA receptor-mediated oIPSCs were also observed in the NAc shell area, and the PPR for the $5 \mathrm{~s}$ interval was $0.45 \pm 0.02(n=12$ cells $/ 6$ mice $)$, similar to the values for oEPSCs and oDAs $(\mathrm{oEPSCs}=0.44 \pm 0.02 ; \mathrm{oDAs}=$ $0.42 \pm 0.01$ ). These results are indicative of similar release properties for GABA from these midbrain DA terminals.

\section{$\mathrm{D}_{2} \mathrm{R}$ agonist inhibits both $\mathrm{DA}$ and glutamate transmission}

Release of DA from midbrain DA neurons is inhibited by activation of $\mathrm{D}_{2} \mathrm{Rs}$ located on the synaptic terminals of these neurons and pulse-train-evoked extracellular dopamine is amplified by a $\mathrm{D}_{2} \mathrm{R}$ antagonist (Kennedy et al., 1992; Trout and Kruk, 1992; Cragg and Greenfield, 1997; Bello et al., 2011). We tested whether glutamate release from midbrain DA neurons is also regulated by activation of $\mathrm{D}_{2} \mathrm{R}$ and compared the dose dependence of the $\mathrm{D}_{2} \mathrm{R}$ effect on oDA transients and oEPSCs.

The $\mathrm{D}_{2} \mathrm{R}$ agonist quinpirole inhibited oDA transients in a dose-dependent manner with the same $\mathrm{IC}_{50}(36 \mathrm{nM})$ shown by quinpirole on eDA transients (Fig. $3 A$ ). However, the maximal inhibition was $90 \pm 1 \%$ for eDA and $77 \pm 2 \%$ for oDA transients $(n=7$ slices $/ 5$ mice; $p=0.00001$; Fig. $3 A, C)$. Quinpirole also inhibited oEPSCs with an $\mathrm{IC}_{50}$ of $20 \mathrm{~nm}$ and a maximal inhibition of $73 \pm 2 \%(n=7$ cells $/ 3$ mice $)$, which closely matches the potency of quinpirole for inhibition of oDA transients (Fig.
B
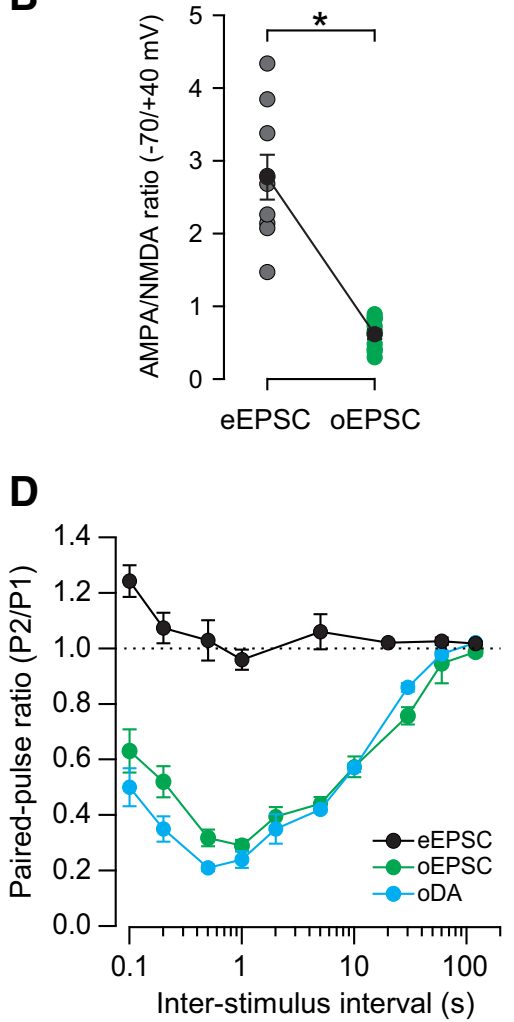

Figure 2. Glutamatergic and dopaminergic responses evoked by optogenetic stimulation of midbrain DA terminals show

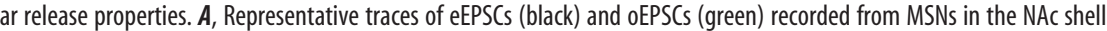

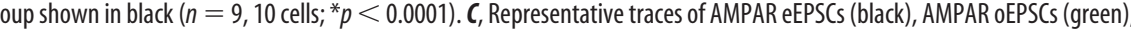
nd oDA transients (blue) evoked by paired-pulse stimulation with 1 s interval. oDA transient evoked by the second pulse (dotted) was calculated by subtracting the single-pulse oDA transients for intervals between 0.1 and 2 s. D, PPRs (P2/P1) for AMPAR eEPSCs (black), AMPAR 0EPSCs (green), and 0DA transients (blue) were plotted as a function of ISI ( $n=7-13$ cells and $6-45$ slices).

$3 B, C)$. In contrast, quinpirole had no effect on eEPSCs $(98 \pm 4 \%$ of the baseline after $1 \mu \mathrm{M}$ quinpirole, $n=9$ cells $/ 3$ mice; Fig. $3 B, C)$. When superimposed, oDA transients and oEPSCs showed similar time courses and maximal effect by quinpirole (Fig. 3D). Furthermore, a $\mathrm{D}_{2} \mathrm{R}$ antagonist, sulpiride $(1 \mu \mathrm{M})$, reversed the inhibition by quinpirole (102 $\pm 4 \%$ for oDA, $n=5$ slices $/ 3$ mice; $86 \pm 12 \%$ for oEPSCs, $n=6$ cells $/ 5$ mice), indicating that the inhibition is mediated by activation of $\mathrm{D}_{2} \mathrm{R}$ in both cases.

\section{Cocaine has different effects on DA and glutamate transmission}

The acute effect of cocaine on DA and glutamate transmission from VTA DA neurons was examined on responses evoked by optogenetic stimulation on the NAc shell. Bath application of cocaine $(10 \mu \mathrm{M}, 10 \mathrm{~min})$ prolonged the oDA transients and increased the decay time from $0.41 \pm 0.02$ to $2.6 \pm 0.2 \mathrm{~s}(n=6$ slices/4 mice; Fig. $4 A$ ). Although the amplitude of the oDA transients was not significantly affected (117 $\pm 9 \%$ of the baseline), in accordance with previous studies (Jones et al., 1995; Budygin et al., 2002), the area was increased by fourfold $(420 \pm 36 \%$ of baseline after cocaine). Subsequent application of sulpiride (1 $\mu \mathrm{M})$ increased the oDA amplitude by $86 \pm 7 \%$ and produced an additional enhancement in the area (542 $\pm 34 \%$ of the baseline; Fig. $4 A$ ). On the contrary, the same concentration of cocaine gradually reduced both the amplitude $(50 \pm 3 \%$ of baseline, 
A eDA oDA

B
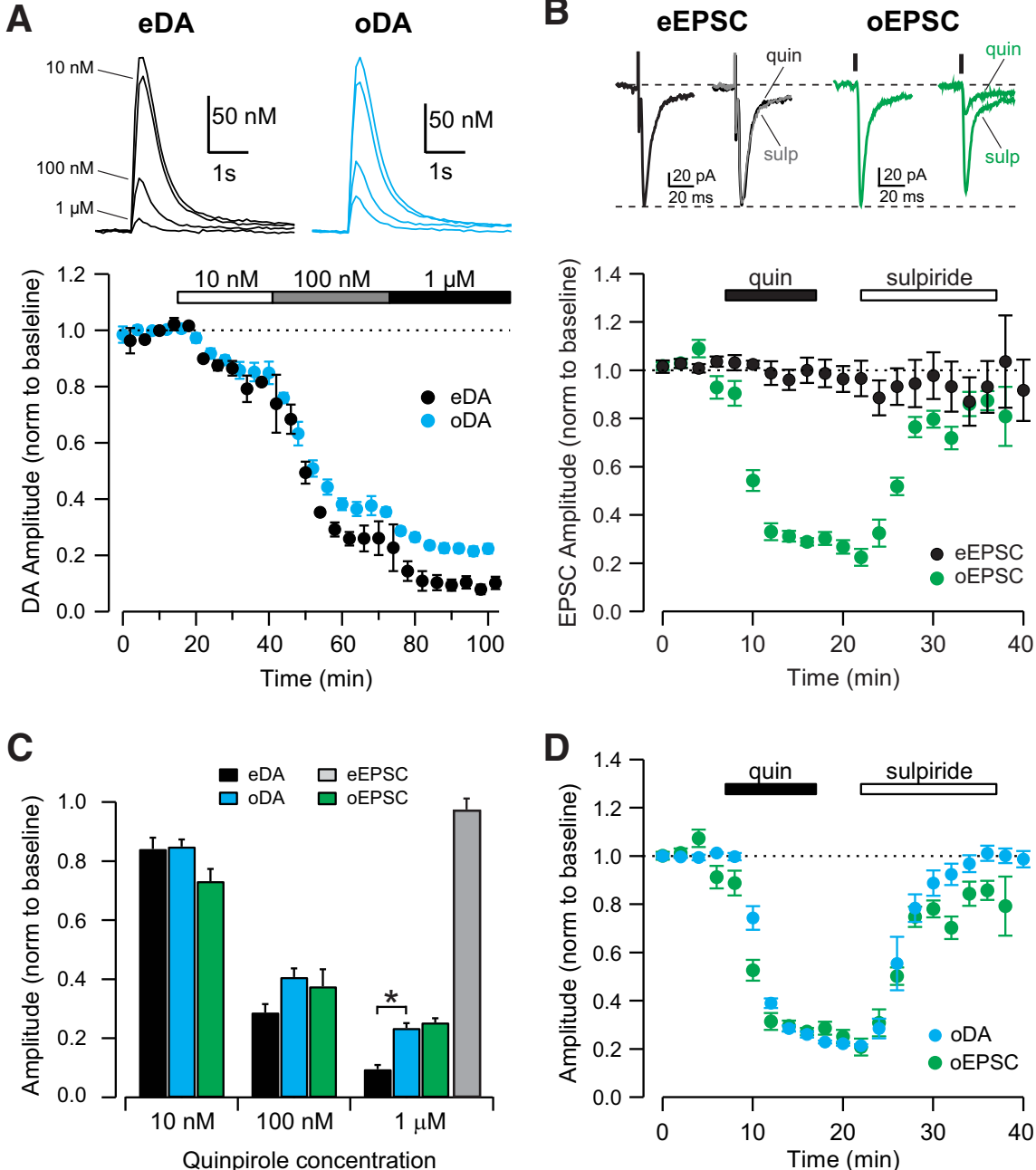
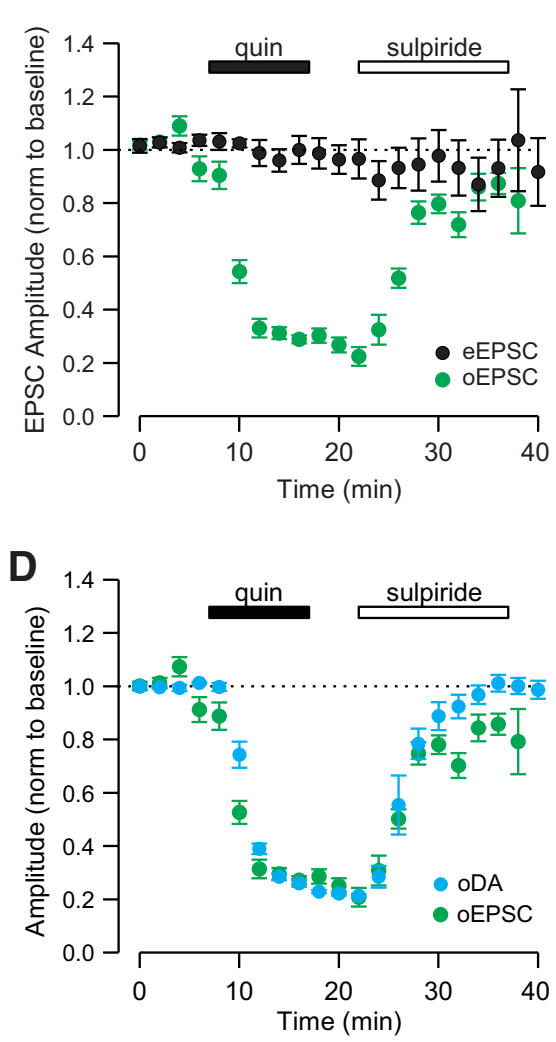

Figure 3. $D_{2}$-like receptor agonist inhibits dopaminergic and glutamatergic transmission from the VTA. $A$, Top, Representative traces of eDA (black) and ODA (blue) transients recorded before and after the application of quinpirole at $10 \mathrm{~nm}, 100 \mathrm{~nm}$, and $1 \mu \mathrm{m}$. Bottom, Time course showing the inhibition of eDA (black) and oDA (blue) transients by increasing concentrations of quinpirole ( $n=7$ slices). $\boldsymbol{B}$, Top, Representative traces of eEPSCs (black) and oEPSCs (green) recorded before and after application of quinpirole (quin; $1 \mu \mathrm{m}$ ) and subsequently sulpiride (sulp; $1 \mu \mathrm{m}$ ). Bottom, Time course of the quinpirole effect on eEPSCs (black) and oEPSCs (green) and subsequent sulpiride $(1 \mu \mathrm{m})$ application ( $n=9,6$ cells). C, Dose-dependent effect of quinpirole on the amplitude of eDA transients (black), oDA transients (blue), oEPSCs (green), and eEPSCs (gray; $n=7$ slices, 9,6 cells; ${ }^{*} p=$ 0.000014 , unpaired $t$ test). $\boldsymbol{D}$, Time course showing the inhibition of oDA transients (blue) and oEPSCs (green) by $1 \mu$ m quinpirole and subsequent reversal by $1 \mu \mathrm{m}$ sulpiride application ( $n=5$ slices, 6 cells).

$n=19$ cells/5 mice; Fig. $4 B)$ and the area $(53 \% \pm 12)$ of the oEPSCs. Subsequent application of sulpiride reversed the depression of oEPSCs by cocaine. Thus, under the same experimental conditions, cocaine enhanced DA transmission but depressed glutamatergic transmission from midbrain DA neurons to NAc.

Because cocaine is a topical anesthetic in addition to being a specific blocker of the monoamine transporter (Dunwiddie et al., 1988; Ruetsch et al., 2001), it is possible that the anesthetic actions could be mediating the differential effect of cocaine on oDA transients and oEPSCs. To rule out this possibility, we tested the effect of nomifensine, another DAT blocker with no reported anesthetic actions (Fig. 4C,D). Similar to cocaine, application of nomifensine $(5 \mu \mathrm{M}, 10 \mathrm{~min})$ slowed down the decay time from $0.42 \pm 0.01$ to $3.0 \pm 0.3 \mathrm{~s}(n=5$ slices $/ 3$ mice $)$, but nomifensine washes out much slower than cocaine, as indicated by the slow $(>60 \mathrm{~min}$ ) reversal of the DA transients decay time constant (Fig. $4 E, F)$ as reported previously (Lee et al., 2001). Nomifensine increased the area of oDA transients by threefold $(314 \pm 43 \%$ of baseline) without an effect on the amplitude (103 $\pm 13 \%$ of baseline; Fig. 4C). Furthermore, subsequent application of sulpiride produced a $67 \pm 9 \%$ increase in the amplitude of oDA transients and an even larger enhancement of the area ( $488 \pm 41 \%$ of baseline). The effect of nomifensine on AMPAR oEPSCs also resembled the cocaine effect and depressed oEPSCs amplitude by $55 \pm 5 \%$. Subsequent sulpiride application reversed the inhibition to $71 \pm 6 \%$ of the baseline by $20 \min (n=5$ cells/3 mice; Fig. $4 D)$.

\section{Presynaptic mechanism for the} cocaine-induced depression of oEPSCs Postsynaptic changes in the number of AMPARs and/or the properties of AMPARs at synapses can account for the cocaineinduced depression of oEPSCs. To test this possibility, the effect of cocaine on NMDARmediated oEPSCs was evaluated. Cocaine $(10 \mu \mathrm{M})$ depressed NMDAR oEPSCs by $44 \pm 8 \%$ to reach a similar level of depression as AMPAR-mediated oEPSCs $(n=5$ cells/4 mice; Fig. 5A). Subsequent application of sulpiride reversed the depression to $103 \pm 6 \%$ of baseline. DAT $T^{+/ I R E S-\text { cre }}$ mice were bred with Drd1-tdTomato mice to identify and record from fluorescently labeled $\mathrm{D}_{1}$ R-expressing MSNs ( $\mathrm{D}_{1}-\mathrm{MSNs}$ ) and from nonfluorescent MSNs presumed to be $\mathrm{D}_{2} \mathrm{R}$-expressing MSNs ( $\mathrm{D}_{2}-\mathrm{MSN}$ ). Cocaine $(10 \mu \mathrm{M})$ induced a $51 \pm 4 \%$ depression of oEPSCs amplitude in $\mathrm{D}_{1}-\mathrm{MSNs}$ and $47 \pm 4 \%$ depression of oEPSCs in $\mathrm{D}_{2}-$ MSNs ( $n=11$ cells and 8 cells/ 6 mice; Fig. $5 B)$. The time course of the depression and the subsequent recovery by sulpiride were undistinguishable in the two subpopulations of MSNs. These results, together with the cocaine-induced depression of NMDAR oEPSCs, argue against a postsynapticmediated depression of oEPSCs, and they strongly suggest that presynaptic changes, such as a decrease in the probability of release, are responsible for the cocaine induced depression of glutamatergic transmission from midbrain DA neurons.

\section{Cocaine inhibits DA and glutamate release via activation of presynaptic $\mathrm{D}_{2} \mathrm{R}$}

How does acute cocaine differentially affect DA and glutamate transmission via a presynaptic mechanism that involves $D_{2} R$ activation? One explanation is that DA and glutamate are released from separate presynaptic compartments with different expression of $\mathrm{D}_{2} \mathrm{R}$ and modulation of vesicle release. However, this appears unlikely because $\mathrm{D}_{2} \mathrm{R}$-mediated inhibition and the release properties of DA and glutamate are extremely similar. An alternative model that explains for differential effect of cocaine on DA and glutamate is described in Figure 6A. The primary effect of cocaine is to block DAT (1) and inhibit DA reuptake. This results in an increase in the extracellular levels of DA that prolongs DA transients (2). At the same time, the 
A
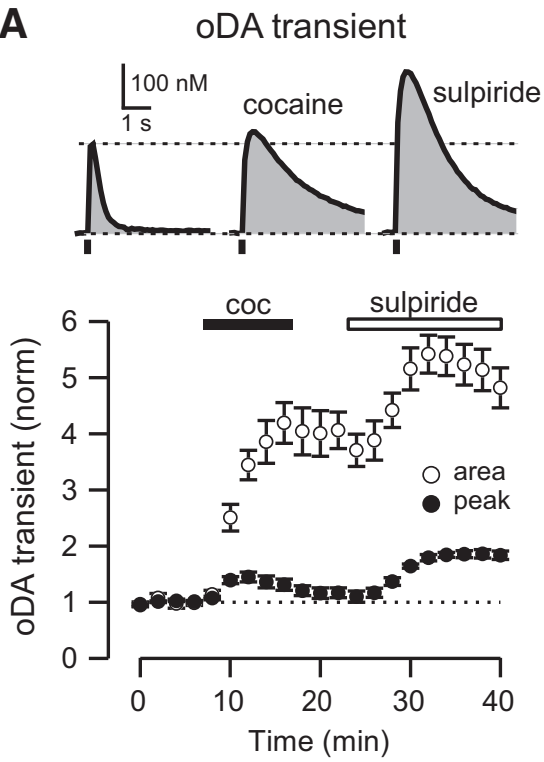

C
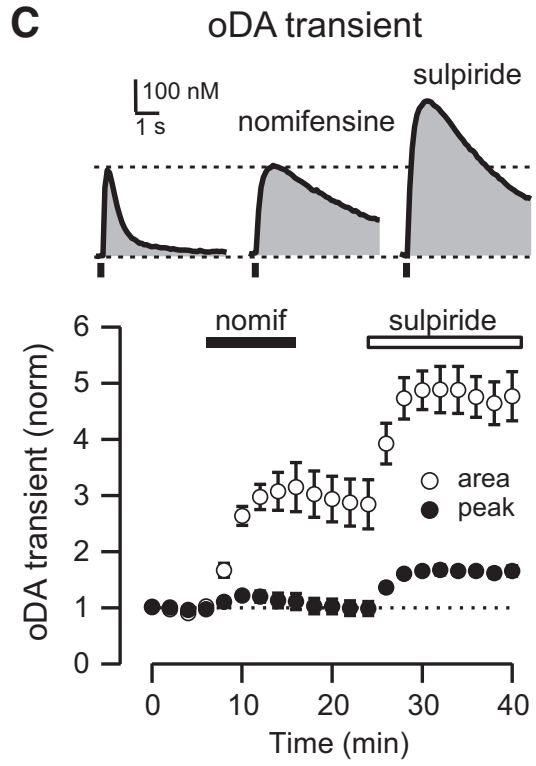

E

oDA transient

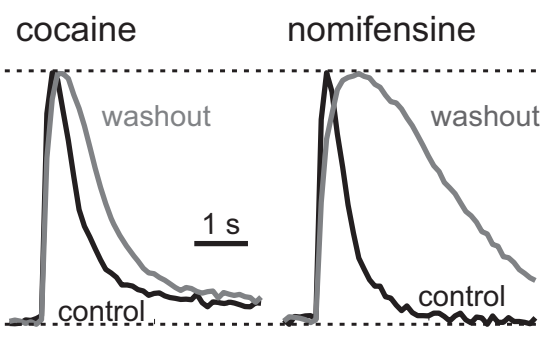

B
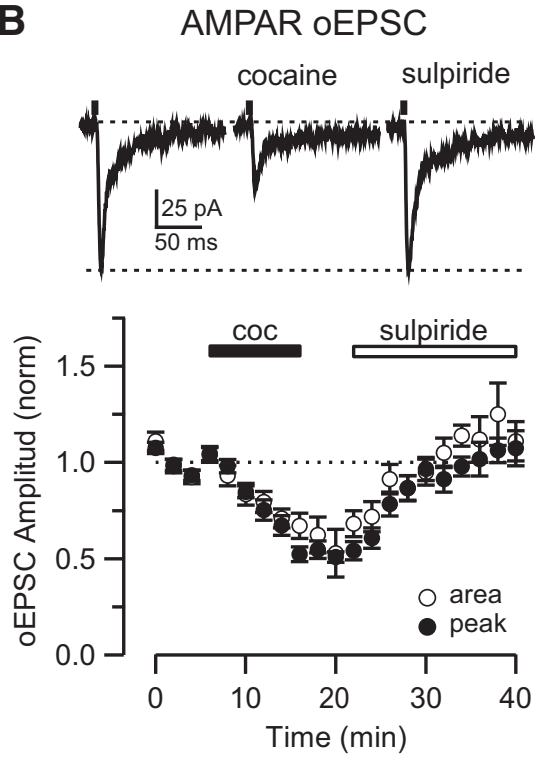

D
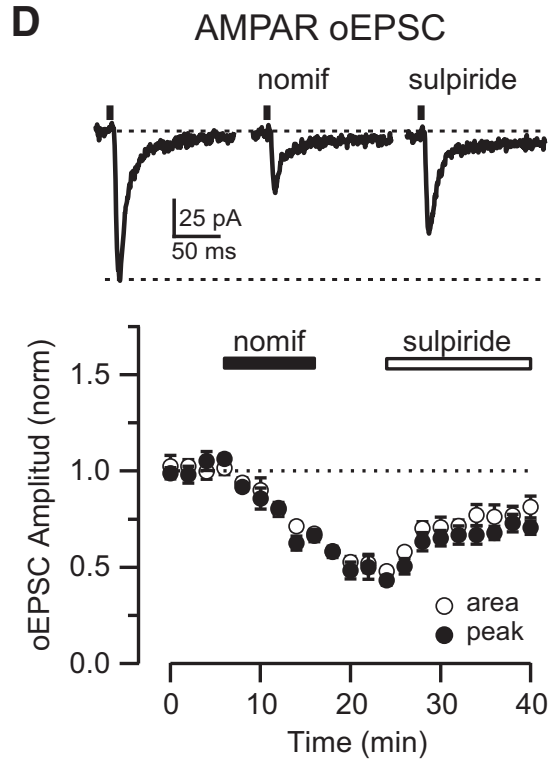

$\mathbf{F}$

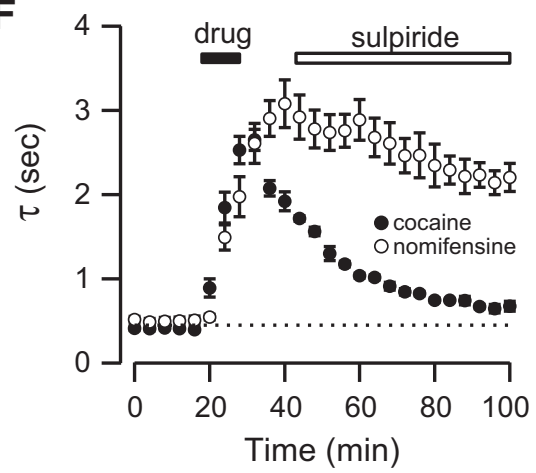

Figure 4. Cocaine enhances DA transients and inhibits glutamate transmission from VTA terminals. $A$, Top, Representative oDA transients recorded in control conditions (left), after $10 \mu \mathrm{m}$ cocaine application (middle), and after subsequent $1 \mu \mathrm{m}$ sulpiride application (right). Bottom, Time course of the change of oDA transient amplitude (solid) and area (open) during cocaine (coc) and subsequent sulpiride application ( $n=6$ slices). $\boldsymbol{B}$, Top, Representative oEPSCs traces recorded in control conditions (left), after 10 $\mu \mathrm{m}$ cocaine application (middle), and after subsequent $1 \mu \mathrm{m}$ sulpiride application (right). Bottom, Time course of the change of oEPSCs amplitude (solid) and area (open) during cocaine and subsequent sulpiride application ( $n=19$ cells). C, Top, Representative oDA transients recorded in control conditions (left), after $5 \mu \mathrm{m}$ nomifensine application (middle), and after subsequent $1 \mu \mathrm{m}$

enhanced extracellular levels of DA facilitate activation of presynaptic $\mathrm{D}_{2} \mathrm{Rs}$ (3), which in turn inhibits DA and glutamate release $(4)$. The $\mathrm{D}_{2} \mathrm{R}$-mediated inhibition of glutamate release explains the observed depression of oEPSCs amplitude that is reversed by sulpiride. Although DA release is also inhibited to a similar degree, there is no significant depression of DA transient amplitude because the inhibition of release is masked and counterbalanced by the increase extracellular levels of DA attributable to a transporter blockade. The inhibition of DA release by cocaine can be revealed by subsequent application of sulpiride, which causes an increase of DA transient amplitude and an additional increase in the area.

This model was tested in experiments that determined the effect of cocaine under conditions in which presynaptic $\mathrm{D}_{2}$ Rs were either blocked pharmacologically or deleted by genetic manipulations. When sulpiride $(1 \mu \mathrm{M})$ was applied throughout the experiments, cocaine now dramatically increased the oDA transient peaks by $75 \pm$ $12 \%(n=7$ slices $/ 3$ mice; Fig. $6 B$ ) but failed to depress AMPAR oEPSCs (95 \pm $9 \%$ of baseline, $n=10$ cells $/ 5$ mice; Fig. $6 \mathrm{C})$. In autoDrd2KO mice, which selectively lack $\mathrm{D}_{2} \mathrm{R}$ in $\mathrm{DA}$ neurons, cocaine also increased oDA transients by $57 \pm$ $8 \%(n=7$ slices $/ 4$ mice; Fig. $6 D)$ and had no effect on AMPAR oEPSCs (91 \pm $11 \%$ of baseline, $n=6$ cells/ 6 mice; Fig. $6 E)$, resembling the effect of cocaine in the presence of sulpiride in wild-type mice. These results are in agreement with the proposed model and strongly suggest that acute cocaine acting on presynaptic $\mathrm{D}_{2} \mathrm{R}$ inhibits $\mathrm{DA}$ and glutamate release from terminals but has a differential effect on glutamate and DA transmission from midbrain DA neuron.

$\leftarrow$

sulpiride application (right). Bottom, Time course of the change of oDA transient amplitude (solid) and area (open) during nomifensine and subsequent sulpiride application ( $n=5$ slices). D, Top, Representative oEPSCs traces recorded in control conditions (left), after $5 \mu \mathrm{m}$ nomifensine application (nomif; middle), and after subsequent $1 \mu \mathrm{m}$ sulpiride application (right). Bottom, Time course of the change of oEPSCs amplitude (solid) and area (open) during nomifensine and subsequent sulpiride application ( $n=5$ cells). $\boldsymbol{E}$, Representative oDA transients in control conditions (black) and $1 \mathrm{~h}$ after cocaine and nomifensine washout (gray). Peaks are normalized to highlight the change in the decay phase of the transients. $\boldsymbol{F}$, Time course of the change in the decay time constant $(\tau)$ of oDA transients during drug (cocaine or nomifensine) application. 
A
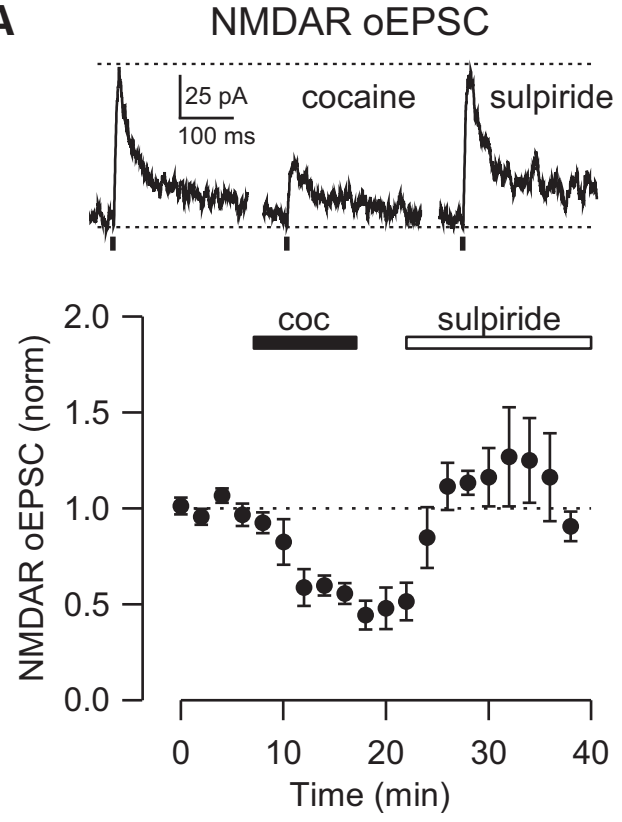

B

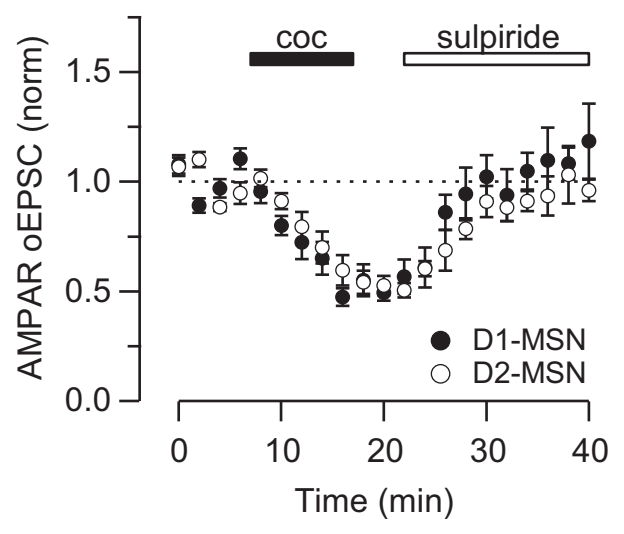

Figure 5. Cocaine inhibits NMDAR-mediated oEPSCs and also AMPAR-mediated oEPSCs in $D_{1}-M S N s$ and $D_{2}-M S N s$. $A$, Top, Representative NMDAR-mediated oEPSCs in control conditions (left), after $10 \mu \mathrm{m}$ cocaine application (middle), and after subsequent $1 \mu \mathrm{m}$ sulpiride application (right). Bottom, Time course of the change of NMDAR-mediated oEPSCs amplitude during cocaine (coc) and subsequent sulpiride application recorded in MSNs in the NAc shell $(n=5$ cells). $\boldsymbol{B}$, Time course of the change of AMPAR-mediated oEPSCs amplitude during cocaine and subsequent sulpiride application recorded from $D_{1}-$ MSNs (solid) and $D_{2}-$ MSNs (open) in the $\operatorname{NAc}$ shell $(n=11,8$ cells).

\section{Discussion}

\section{DA and glutamate release from DA terminals}

In this study, we explored the properties and modulation of DA and glutamate transmission in the NAc shell using electrical and optogenetic stimulation. Although the electrical stimulation activates all nearby axons, optogenetic stimulation activates only ChR2-expressing fibers from mesolimbic dopaminergic neurons. The postsynaptic responses and DA transients evoked by these different approaches showed similarities and differences. DA transients in the NAc shell evoked by electrical or optogenetic stimulation were undistinguishable with regards to the following: (1) the current-voltage plots that showed the characteristic profile for DA molecules; (2) the amplitude, decay time constant, and delay from stimulation; and (3) their sensitivity to TTX, which indicates a requirement for voltage-dependent sodium channels and action potentials. Glutamate-mediated EPSCs mea- sured from MSNs in the NAc shell also shared some properties between those evoked by electrical or optogenetic stimulation, such as the similar delay to the onset of response after stimulation and the activation of postsynaptic AMPA and NMDA ionotropic receptors. However, the AMPA/NMDA ratio was threefold larger in the glutamatergic synapses evoked by electrical stimulation than the optogenetic stimulation. This suggests that glutamatergic inputs from midbrain DA neurons have different postsynaptic properties from the majority of glutamatergic inputs that originate in the cortex, amygdala, thalamus, and hippocampus. The relatively larger NMDAR component observed in oEPSCs also suggests a potential for triggering a larger postsynaptic calcium signal in MSN dendrites in response to activation of glutamatergic inputs from midbrain DA neurons.

When comparing oDA and oEPSCs, the PPR, a measure of use-dependent plasticity that triggers changes in the probability of neurotransmitter release when consecutive stimulations are delivered close in time, proved informative. Most striking, oEPSCs showed a marked paired-pulse depression that takes up to $120 \mathrm{~s}$ for a full recovery. On the contrary, eEPSCs showed a moderate paired-pulse facilitation with ISIs of 100-200 ms and no paired-pulse effect with ISIs longer than $500 \mathrm{~ms}$, which agrees with previous findings (Grueter et al., 2010). This strongly suggests that the properties of glutamate release in midbrain DA terminals are profoundly different from other "typical" glutamatergic terminal. In fact, the PPR characteristics of oEPSCs were similar to oDA, and they also resemble the characteristics described previously using electrical stimulation (Phillips et al., 2002). Furthermore, both oEPSCs and oDA were similarly depressed by the $\mathrm{D}_{2}$-like receptor agonist quinpirole with regards to $\mathrm{IC}_{50}$, maximal inhibition, and time course, and the depression of oEPSCs and oDAs were fully reversed by the $\mathrm{D}_{2} \mathrm{R}$ antagonist sulpiride. These results indicate that midbrain projections that release glutamate and DA have presynaptic $\mathrm{D}_{2} \mathrm{R}$ that can negatively modulate release. In contrast, eEPSCs were insensitive to quinpirole, indicating that most other glutamatergic terminals in the NAc shell lack presynaptic $\mathrm{D}_{2}$ Rs. Together, our findings show that the properties of glutamate release from DA terminals are very similar to those of DA-releasing terminals from midbrain neurons and are different from the properties of glutamate release from cortical terminals.

Previous biochemical studies provide evidence in support of glutamate and DA corelease from the same vesicle and terminals. VMAT2 and VGluT2 were found to coimmunoprecipitate in subcellular fractions of synaptic vesicles, and glutamate cotransport was shown to stimulate monoamine uptake into the synaptic vesicles (Hnasko et al., 2010). However, electron-microscopic studies showed only sporadic VGluT2-TH double staining in varicosities of the NAc (Kawano et al., 2006; Moss et al., 2011), and VGluT2 and TH are found to colocalize in immature NAc terminals but not in adult rats (Bérubé-Carrière et al., 2009). The lack of colabeling for VGluT2 and TH within the same terminal was interpreted as evidence of segregation of VGluT2-containing and TH-containing terminals. The results from our current study favor rather than rule out the idea that DA and glutamate are released from the same presynaptic compartments in VTA dopaminergic neurons.

\section{Electrical versus optogenetic stimulation of DA release}

Previous studies demonstrated that optogenetic evoked DA transients were for the most part similar to those evoked by electrical stimulation (Tecuapetla et al., 2010; Rice et al., 2011). Here we showed that the maximal inhibition induced by a saturating con- 
A

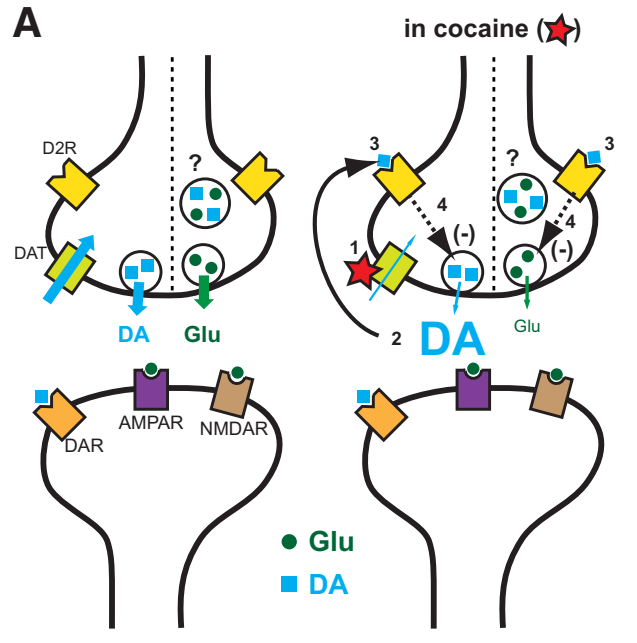

B

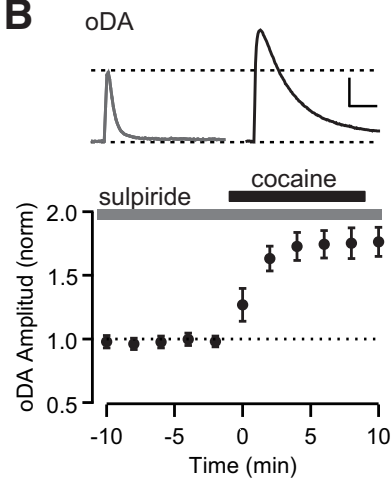

D
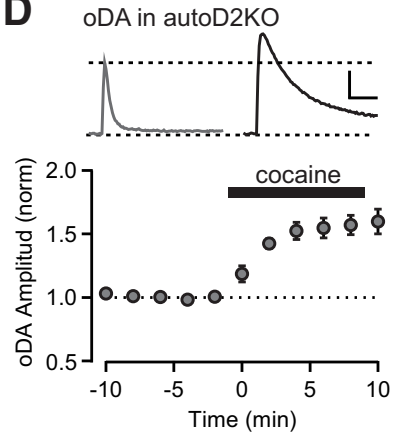

C AMPAR oEPSC
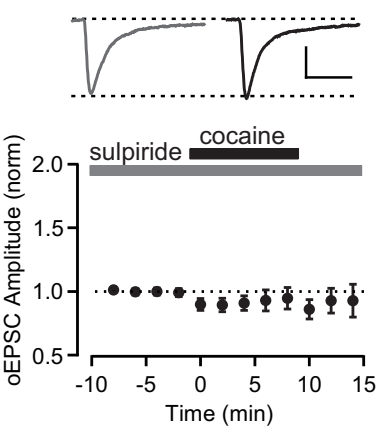

E AMPAR oEPSC in autoD2KO

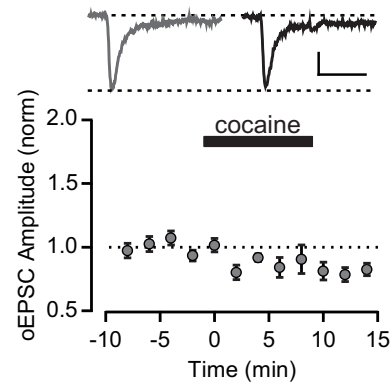

Figure 6. Cocaine inhibits glutamate and DA release via activation of presynaptic $D_{2} R s . A$, Diagram showing a possible mechanism of action of cocaine on the synaptic terminals from the VTA that release dopamine (DA; blue square) and glutamate (Glu; green circle) or both. Under control conditions (left), DA and glutamate are released in response to action potentials and activate mainly postsynaptic receptors. DAT uptakes DA from the synaptic cleft, keeping extracellular DA concentration low. In the presence of cocaine (right), DAT is blocked and DA reuptake is inhibited (1), causing an increase in extracellular DA level (2), that leads to activation of presynaptic $D_{2} R(3)$ and subsequent inhibition of $D A$ and glutamate release (4). Thus, as cocaine inhibits $D A$ and $G l u$ release via activation of presynaptic $D_{2} R$, it causes opposite actions on the neurotransmission, increasing $D A$ but inhibiting glutamate transmission. $\boldsymbol{B}$, Top, Representative $0 D A$ transients recorded in sulpiride (left) and sulpiride + cocaine (right). Scale bars: $2 \mathrm{~s}, 100 \mathrm{~nm}$. Bottom, Time course of the change of oDA transient amplitude during $10 \mu \mathrm{m}$ cocaine application in the constant presence of $1 \mu \mathrm{m}$ sulpiride ( $n=7$ slices).C, Top, Representative oEPSCstraces recorded in sulpiride (left) and sulpiride + cocaine (right). Bottom, Time course of the change of oEPSCs amplitude during $10 \mu \mathrm{m} \mathrm{cocaine}$ application in the constant presence of $1 \mu \mathrm{m}$ sulpiride ( $n=6$ cells). Scale bars: $25 \mathrm{~ms}, 50 \mathrm{pA}$. D. Top, Representative oDA transients in autoDrd2KO mice recorded before (left) and after (right) application of cocaine. Scale bars: $2 \mathrm{~s}, 50 \mathrm{~nm}$. Bottom, Time course of the change of oDA transient amplitude recorded in autoDrd2KO mice during $10 \mu \mathrm{m}$ cocaine application ( $n=7$ slices). $E$, Top, Representative oEPSCs traces recorded in autoDrd2KO mice before (left) and after (right) cocaine. Scale bars: $25 \mathrm{~ms}, 25 \mathrm{pA}$. Bottom, Time course of the change of oEPSCs amplitude recorded in autoDrd2KO mice during $10 \mu \mathrm{m}$ cocaine application ( $n=7$ cells). All data are mean \pm SEM.

centration of quinpirole $(1 \mu \mathrm{M})$ was higher for eDA than oDA $(90$ vs $77 \%$, respectively). Although optogenetic stimulation activates selectively midbrain dopaminergic afferents in the NAc, electrical stimulation activates all passing fibers, dopaminergic axons and all other passing fibers, causing the release of DA and others neurotransmitters that can affect DA signals as well. Previous studies have shown that a large component of the DA transients evoked by electrical stimulation are blocked by nicotinic acetylcholine receptor antagonists (Zhou et al., 2001), and a recent study showed that the activation of cholinergic interneurons is sufficient to evoke DA release by released acetylcholine and activation of nicotinic acetylcholine receptors on DA neuron terminals (Cachope et al., 2012; Threlfell et al., 2012). Because the release of acetylcholine from cholinergic interneurons is depressed by $\mathrm{D}_{2} \mathrm{R}$ on its terminal (Gifford and Johnson, 1992; DeBoer et al., 1996), the application of quinpirole not only depresses the release of DA but also the release of acetylcholine, thereby resulting in larger depression of eDA compared with oDA.

\section{Cocaine actions on DA and glutamate release from DA terminals}

The NAc shell is required for the acquisition of several cocainerelated behaviors, such as conditioned place preference, locomotor sensitization, and operant intravenous self-administration (Di Chiara et al., 2004; Wise, 2004; Ikemoto and Bonci, 2014).
Repeated exposure to cocaine induces long-term changes at glutamatergic synapses onto the MSNs (Nestler, 2001; Thomas et al., 2001). Furthermore, manipulation of glutamatergic signaling in the NAc controls drug-seeking behavior in animal models of addiction (Kalivas, 2004; Self et al., 2004). Although glutamatergic transmission from VTA DA neurons onto MSNs represents a small proportion of all glutamatergic inputs to MSNs, it appears able to regulate the physiological response to stimulant drugs. VGluT2 conditional knock-out mice in DA neurons display altered locomotor response to amphetamine (Birgner et al., 2010) and cocaine (Hnasko et al., 2010) and enhanced sucrose and cocaine self-administration (Alsiö et al., 2011). Thus, a better understanding of the properties and the effect of cocaine on this excitatory glutamatergic transmission from VTA DA neurons are critical.

Previous studies have claimed that cocaine can increase DA release and contribute to the enhancement of DA transmission in the striatum (Lee et al., 2001; Kile et al., 2010). However, in mice lacking DAT, cocaine did not increase evoked DA release, suggesting that cocaine does not affect the release machinery directly (Budygin et al., 2002). This view was further supported by other findings that DAT inhibitors, such as cocaine, inhibit DA release at high concentrations by facilitating the activation of presynaptic $\mathrm{D}_{2}$ Rs (Wieczorek and Kruk, 1994; John and Jones, 2007). In this study, we show that cocaine produced a rapid increase in the 
decay time constant of oDA transient and dramatically enhanced the area with little effect on the peak amplitude. In contrast, cocaine depressed the peak and the area of both AMPAR- and NMDAR-mediated oEPSCs by $\sim 50 \%$ in both subpopulations of MSNs in the NAc shell ( $D_{1} \mathrm{R}$ - and $\mathrm{D}_{2} \mathrm{R}$-expressing MSNs). Although the $\mathrm{D}_{2} \mathrm{R}$ antagonist sulpiride further enhanced both the peak amplitude and the area of oDA transients, sulpiride reversed the cocaine-induced depression in oEPSCs.

Similar results were obtained with nomifensine, a DAT blocker with no described anesthetic actions, ruling out possible nonspecific actions of cocaine. There was a small difference in the recovery of the oEPSCs depression by sulpiride between cocaine and nomifensine. Cocaine-induced depression was completely reversed by sulpiride, and nomifensine-induced depression was reversed to $70 \%$ of baseline after 20 min sulpiride application. It is possible that the slower washout properties of nomifensine might contribute to the difference (Lee et al., 2001).

We propose a parsimonious model to explain the differential effects of cocaine on DA and glutamate transmission from midbrain DA neurons. Cocaine blocks DAT and inhibits DA reuptake, resulting in increased DA levels that cause activation of presynaptic $\mathrm{D}_{2} \mathrm{R}$ and depression of both DA and glutamate release. The inhibition of DA release explains why the peak of DA transients do not increase and remains mainly undisturbed after cocaine. The model was tested by two complementary and independent experiments. When the inhibition of DA and glutamate release by presynaptic $\mathrm{D}_{2} \mathrm{R}$ was blocked pharmacologically, cocaine increased the peak amplitude of the oDA transients with no change in the oEPSCs. Conversely, when transgenic mice lacking presynaptic $\mathrm{D}_{2}$ Rs only in midbrain dopaminergic neurons were used (Bello et al., 2011), the same enhancement of DA peak with no change in oEPSCs was observed after cocaine application. These results from the pharmacological and genetic blockade of presynaptic $\mathrm{D}_{2}$ Rs are in agreement with the proposed model and indicate that acute cocaine by increasing extracellular DA levels enhances the $\mathrm{D}_{2} \mathrm{R}$-mediated feedback inhibition of DA and glutamate release but has an overall differential effect on DA and glutamate transmission from midbrain DA neurons.

\section{Conclusions}

Here we showed that the properties of glutamatergic transmission evoked by optogenetic stimulation of midbrain DA terminals in the NAc shell are different from those of glutamatergic inputs evoked by electrical stimulation of nearby glutamatergic axons because they showed a small AMPA/NMDA ratio and a marked PPR depression and because they are modulated by $\mathrm{D}_{2} \mathrm{R}$ agonists. On the contrary, the properties of oEPSCs were very similar to those of oDA transients evoked by activation of midbrain DA terminals, indicating that glutamate and DA can be released or coreleased from the same midbrain terminal. Furthermore, our results show that cocaine, when blocking the DA reuptake, promotes feedback inhibition of glutamate and DA release through presynaptic $\mathrm{D}_{2}$ Rs in midbrain DA neurons and has opposite overall effects on glutamate and DA transmission from midbrain neurons.

\section{References}

Alsiö J, Nordenankar K, Arvidsson E, Birgner C, Mahmoudi S, Halbout B, Smith C, Fortin GM, Olson L, Descarries L, Trudeau LÉ, Kullander K, Lévesque D, Wallén-Mackenzie A (2011) Enhanced sucrose and cocaine self-administration and cue-induced drug seeking after loss of VGLUT2 in midbrain dopamine neurons in mice. J Neurosci 31:12593-12603. CrossRef Medline

Bäckman CM, Malik N, Zhang Y, Shan L, Grinberg A, Hoffer BJ, Westphal H,
Tomac AC (2006) Characterization of a mouse strain expressing Cre recombinase from the $3^{\prime}$ untranslated region of the dopamine transporter locus. Genesis 44:383-390. CrossRef Medline

Bello EP, Mateo Y, Gelman DM, Noaín D, Shin JH, Low MJ, Alvarez VA, Lovinger DM, Rubinstein M (2011) Cocaine supersensitivity and enhanced motivation for reward in mice lacking dopamine D2 autoreceptors. Nat Neurosci 14:1033-1038. CrossRef Medline

Bérubé-Carrière N, Riad M, Dal Bo G, Lévesque D, Trudeau LE, Descarries L (2009) The dual dopamine-glutamate phenotype of growing mesencephalic neurons regresses in mature rat brain. J Comp Neurol 517:873891. CrossRef Medline

Bérubé-Carrière N, Guay G, Fortin GM, Kullander K, Olson L, WallénMackenzie Å, Trudeau LE, Descarries L (2012) Ultrastructural characterization of the mesostriatal dopamine innervation in mice, including two mouse lines of conditional VGLUT2 knockout in dopamine neurons. Eur J Neurosci 35:527-538. CrossRef Medline

Birgner C, Nordenankar K, Lundblad M, Mendez JA, Smith C, le Grevès M, Galter D, Olson L, Fredriksson A, Trudeau LE, Kullander K, WallénMackenzie A (2010) VGLUT2 in dopamine neurons is required for psychostimulant-induced behavioral activation. Proc Natl Acad Sci U S A 107:389-394. CrossRef Medline

Budygin EA, John CE, Mateo Y, Jones SR (2002) Lack of cocaine effect on dopamine clearance in the core and shell of the nucleus accumbens of dopamine transporter knock-out mice. J Neurosci 22:RC222(1-4). Medline

Cachope R, Mateo Y, Mathur BN, Irving J, Wang HL, Morales M, Lovinger DM, Cheer JF (2012) Selective activation of cholinergic interneurons enhances accumbal phasic dopamine release: setting the tone for reward processing. Cell Rep 2:33-41. CrossRef Medline

Chuhma N, Zhang H, Masson J, Zhuang X, Sulzer D, Hen R, Rayport S (2004) Dopamine neurons mediate a fast excitatory signal via their glutamatergic synapses. J Neurosci 24:972-981. CrossRef Medline

Cragg SJ, Greenfield SA (1997) Differential autoreceptor control of somatodendritic and axon terminal dopamine release in substantia nigra, ventral tegmental area, and striatum. J Neurosci 17:5738-5746. Medline

Dal Bo G, St-Gelais F, Danik M, Williams S, Cotton M, Trudeau LE (2004) Dopamine neurons in culture express VGLUT2 explaining their capacity to release glutamate at synapses in addition to dopamine. J Neurochem 88:1398-1405. CrossRef Medline

Dal Bo G, Bérubé-Carrière N, Mendez JA, Leo D, Riad M, Descarries L, Lévesque D, Trudeau LE (2008) Enhanced glutamatergic phenotype of mesencephalic dopamine neurons after neonatal 6-hydroxydopamine lesion. Neuroscience 156:59-70. CrossRef Medline

DeBoer P, Heeringa MJ, Abercrombie ED (1996) Spontaneous release of acetylcholine in striatum is preferentially regulated by inhibitory dopamine D2 receptors. Eur J Pharmacol 317:257-262. CrossRef Medline

Di Chiara G, Bassareo V, Fenu S, De Luca MA, Spina L, Cadoni C, Acquas E, Carboni E, Valentini V, Lecca D (2004) Dopamine and drug addiction: the nucleus accumbens shell connection. Neuropharmacology 47 [Suppl 1]:227-241.

Dunwiddie TV, Proctor WR, Tyma J (1988) Local anaesthetic actions of cocaine: effects on excitatory and inhibitory synaptic responses in the hippocampus in vitro. Br J Pharmacol 95:1117-1124. CrossRef Medline

Franklin KBJ, Paxinos G (2007) The mouse brain in stereotaxic coordinates, Ed 3. Amsterdam: Elsevier.

Gifford AN, Johnson KM (1992) Effect of chronic cocaine treatment on D2 receptors regulating the release of dopamine and acetylcholine in the nucleus accumbens and striatum. Pharmacol Biochem Behav 41:841846. CrossRef Medline

Grueter BA, Brasnjo G, Malenka RC (2010) Postsynaptic TRPV1 triggers cell type-specific long-term depression in the nucleus accumbens. Nat Neurosci 13:1519-1525. CrossRef Medline

Hnasko TS, Chuhma N, Zhang H, Goh GY, Sulzer D, Palmiter RD, Rayport S, Edwards RH (2010) Vesicular glutamate transport promotes dopamine storage and glutamate corelease in vivo. Neuron 65:643-656. CrossRef Medline

Ikemoto S, Bonci A (2014) Neurocircuitry of drug reward. Neuropharmacology 76:329-341. CrossRef Medline

John CE, Jones SR (2007) Voltammetric characterization of the effect of monoamine uptake inhibitors and releasers on dopamine and serotonin uptake in mouse caudate-putamen and substantia nigra slices. Neuropharmacology 52:1596-1605. CrossRef Medline 
Jones SR, Garris PA, Wightman RM (1995) Different effects of cocaine and nomifensine on dopamine uptake in the caudate-putamen and nucleus accumbens. J Pharmacol Exp Ther 274:396-403. Medline

Kalivas PW (2004) Glutamate systems in cocaine addiction. Curr Opin Pharmacol 4:23-29. CrossRef Medline

Kawano M, Kawasaki A, Sakata-Haga H, Fukui Y, Kawano H, Nogami H, Hisano S (2006) Particular subpopulations of midbrain and hypothalamic dopamine neurons express vesicular glutamate transporter 2 in the rat brain. J Comp Neurol 498:581-592. CrossRef Medline

Kennedy RT, Jones SR, Wightman RM (1992) Dynamic observation of dopamine autoreceptor effects in rat striatal slices. J Neurochem 59:449455. CrossRef Medline

Kile BM, Guillot TS, Venton BJ, Wetsel WC, Augustine GJ, Wightman RM (2010) Synapsins differentially control dopamine and serotonin release. J Neurosci 30:9762-9770. CrossRef Medline

Lee TH, Balu R, Davidson C, Ellinwood EH (2001) Differential time-course profiles of dopamine release and uptake changes induced by three dopamine uptake inhibitors. Synapse 41:301-310. CrossRef Medline

Lee TH, Gee KR, Davidson C, Ellinwood EH (2002) Direct, real-time assessment of dopamine release autoinhibition in the rat caudate-putamen. Neuroscience 112:647-654. CrossRef Medline

Mendez JA, Bourque MJ, Dal Bo G, Bourdeau ML, Danik M, Williams S, Lacaille JC, Trudeau LE (2008) Developmental and target-dependent regulation of vesicular glutamate transporter expression by dopamine neurons. J Neurosci 28:6309-6318. CrossRef Medline

Moss J, Ungless MA, Bolam JP (2011) Dopaminergic axons in different divisions of the adult rat striatal complex do not express vesicular glutamate transporters. Eur J Neurosci 33:1205-1211. CrossRef Medline

Nestler EJ (2001) Molecular basis of long-term plasticity underlying addiction. Nat Rev Neurosci 2:119-128. CrossRef Medline

Phillips PE, Hancock PJ, Stamford JA (2002) Time window of autoreceptormediated inhibition of limbic and striatal dopamine release. Synapse 44: 15-22. CrossRef Medline

Rice ME, Patel JC, Cragg SJ (2011) Dopamine release in the basal ganglia. Neuroscience 198:112-137. CrossRef Medline

Ruetsch YA, Böni T, Borgeat A (2001) From cocaine to ropivacaine: the history of local anesthetic drugs. Curr Top Med Chem 1:175-182. CrossRef Medline

Self DW, Choi KH, Simmons D, Walker JR, Smagula CS (2004) Extinction training regulates neuroadaptive responses to withdrawal from chronic cocaine self-administration. Learn Mem 11:648-657. CrossRef Medline

Shuen JA, Chen M, Gloss B, Calakos N (2008) Drd1a-tdTomato BAC transgenic mice for simultaneous visualization of medium spiny neurons in the direct and indirect pathways of the basal ganglia. J Neurosci 28:26812685. CrossRef Medline

Stuber GD, Hnasko TS, Britt JP, Edwards RH, Bonci A (2010) Dopaminergic terminals in the nucleus accumbens but not the dorsal striatum corelease glutamate. J Neurosci 30:8229-8233. CrossRef Medline

Sulzer D, Joyce MP, Lin L, Geldwert D, Haber SN, Hattori T, Rayport S (1998) Dopamine neurons make glutamatergic synapses in vitro. J Neurosci 18:4588-4602. Medline

Tecuapetla F, Patel JC, Xenias H, English D, Tadros I, Shah F, Berlin J, Deisseroth K, Rice ME, Tepper JM, Koos T (2010) Glutamatergic signaling by mesolimbic dopamine neurons in the nucleus accumbens. J Neurosci 30:7105-7110. CrossRef Medline

Thomas MJ, Beurrier C, Bonci A, Malenka RC (2001) Long-term depression in the nucleus accumbens: a neural correlate of behavioral sensitization to cocaine. Nat Neurosci 4:1217-1223. CrossRef Medline

Threlfell S, Lalic T, Platt NJ, Jennings KA, Deisseroth K, Cragg SJ (2012) Striatal dopamine release is triggered by synchronized activity in cholinergic interneurons. Neuron 75:58-64. CrossRef Medline

Tritsch NX, Ding JB, Sabatini BL (2012) Dopaminergic neurons inhibit striatal output through non-canonical release of GABA. Nature 490:262-266. CrossRef Medline

Trout SJ, Kruk ZL (1992) Differences in evoked dopamine efflux in rat caudate putamen, nucleus accumbens and tuberculum olfactorium in the absence of uptake inhibition: influence of autoreceptors. Br J Pharmacol 106:452-458. CrossRef Medline

Venton BJ, Seipel AT, Phillips PE, Wetsel WC, Gitler D, Greengard P, Augustine GJ, Wightman RM (2006) Cocaine increases dopamine release by mobilization of a synapsin-dependent reserve pool. J Neurosci 26:32063209. CrossRef Medline

Wieczorek WJ, Kruk ZL (1994) A quantitative comparison on the effects of benztropine, cocaine and nomifensine on electrically evoked dopamine overflow and rate of re-uptake in the caudate putamen and nucleus accumbens in the rat brain slice. Brain Res 657:42-50. CrossRef Medline

Wise RA (2004) Dopamine, learning and motivation. Nat Rev Neurosci 5:483-494. CrossRef Medline

Yamaguchi T, Wang HL, Li X, Ng TH, Morales M (2011) Mesocorticolimbic glutamatergic pathway. J Neurosci 31:8476-8490. CrossRef Medline

Yamaguchi T, Wang HL, Morales M (2013) Glutamate neurons in the substantia nigra compacta and retrorubral field. Eur J Neurosci 38:36023610. CrossRef Medline

Zhou FM, Liang Y, Dani JA (2001) Endogenous nicotinic cholinergic activity regulates dopamine release in the striatum. Nat Neurosci 4:12241229. CrossRef Medline 